\title{
Strategic Agility and the Global Pandemic: The Agile Organizational Structure, A Theoretical Review
}

\author{
Michael A. Arokodare ${ }^{1} \&$ Blessing R. Falana ${ }^{2}$ \\ ${ }^{1}$ Department of Business Administration \& Marketing, Babcock University, Illishan, Ogun State, Nigeria \\ 2Department of Business Administration, Dominican University, Samonda, Ibadan, Nigeria \\ biodunarokodare@yahoo.com, falana.r@dui.edu.ng
}

\begin{abstract}
Literature has shown that university institutions cannot survive global pandemic shock-like COVID-19 as well as achieve sound outcomes without putting in place an agile or flexible organizational structure. However, most university institutions in Nigeria especially public university institutions recorded poor outcomes in terms of marketing, customer/student satisfaction and operations management. The purpose of this paper was to establish how agile or flexible organizational structure enhances the link between strategic agility and university institutional outcomes. Considering past empirical studies reviewed, the study proposed that strategic agility has a positive influence on organizational outcomes in institutions of higher education; and that flexible or agile organizational structure has a positive mediating influence on the relationship between strategic agility and organizational outcomes. A conceptual model to guide the further investigation in future studies was developed depicting the interaction between strategic agility and organizational outcomes with flexible organizational structure as a mediator. The paper concluded that agile or flexible organizational structure enhances strategic agility and sound outcomes of university institutions. The study recommended that these institutions must be able to think strategically with an agile mindset, understand mistakes, learn lessons quickly, and continuously adjust and readjust their strategic direction in order to develop innovative ways to create value. They must also empower their academic and non-academic staff teams on dynamic and modern marketing approaches to manage unexpected events to enhance marketing performance, student satisfaction and sound operations management.
\end{abstract}

Keywords: Agile organizational structure, COVID-19 pandemic, Dynamic capabilities, Organisational outcomes, Strategic agility.

\section{Introduction}

The prevailing turbulent business environment characterized by globalization, digitization, global trade liberalization, interconnectivity and global pandemic, has thrown many organizations into situations with pervasive volatility, uncertainty, complexity and ambiguity. It is only those organizations (including higher educational institutions) with the capability of flexibility in structure and operations, in the face of rapidly emerging waves of change, fast modification of their strategic course and can develop inventive ways to create value, that are likely to build and maintain competitive advantages and deliver on organizational outcomes. Organizational structure is a way by which the activities carried out by the organization are organized, divided and coordinated by taking the various elements and the relations between the elements as a unit (Monavarian, Asgari, \& Ashna, 2007). It is the expression of systematic thinking and it comprises the fundamental structure of organizational units of hierarchy (Ahmady, Mehrpour, \& Nikooravesh, 2016). Organizational structure is described as a way of apportioning responsibilities to determined duties and coordinating them.

The global COVID-19 pandemic has caused a lot of changes to most organizational structures. Hence, most organizations lengthened their operational functions and established alerts as well as fast responses to threats and unexpected events in their business environment. In this regard, multinational organizations tend to be accurate and got it right in responding to changes than small organizations, and this enabled them to have a higher survival rate than the small organizations (Rugraff \& Hansen, 2011). Small and medium organizations tend to survive in the economy because they contribute to the Gross Domestic Product (GDP) of the countries especially in the area of the creation of employment opportunities (Gerald, Obianuju, \& Chukwunonso, 2020). Giving credence to this assertion, Aga, Francis, and Meza (2015) and Govuzela and Mafini (2019) opined that organizations play a strategic role in the economic development of many countries. The size and scope of organizational performance is highly contingent on the external environment: its complexity, its dynamism and its munificence (Chen et al., 2014). In effect, the turbulence of the business environment has a significant effect on the performance of organizations (Arokodare \& Asikhia, 2020; 
Nnamani \& Ajagu, 2014). Which means that organizations that survived during turbulent periods are those that can easily respond to changes? Aghina, De Smet, and Weerda (2015) asserted that it is those organizations that are strategically agile that are resilient, reliable, and efficient (that is stable) and at the same time are fast, nimble, and adaptive (that is dynamic). These features are attributed to organizations that are agile and have very good structures capable of weathering the storms of the environment.

The COVID-19 Global Pandemic: In Africa and indeed Nigeria, organizations are facing different levels of difficulties such as policy inconsistency, poor infrastructure (light, water, roads and other public utilities). The government's lack of incentives, a pitiful regulatory system, and an institutional vacuum are also some of the difficulties facing business organizations in this region(Doh et al., 2017). These issues have been exacerbated by the government's current strategy of shutting down organizations in reaction to the COVID-19 pandemic that has ravaged many economies around the world, including Nigeria. COVID-19 became a global pandemic in March 2020, causing the destruction of economic activities and school functions (Ciotti et al., 2020). According to Liu, Lee, and Lee (2020), the pandemic has caused serious problems for all economies worldwide: loss of hundreds of thousands of human lives, and exposure of the inadequacies and institutional weaknesses of all national health systems. Without exception, the COVID-19 pandemic has caused serious disruptions to national economies and wreaked untold havoc on certain critical sectors of the global economy.

COVID-19 as a global pandemic created an unexpected shock syndrome to school marketing functions, student satisfaction, organizational structure and operational management of many schools across all countries. The global pandemic crippled economic and various school (organizations) activities across developed, emerging and developing countries resulting from a spike in death and lack of immediate provision of vaccine to cure the global disease. Universities (organizations) across countries are continuously conscious of whether or not they will survive or overcome the shock engendered by the global pandemic and ever-competitive business environment. It is in this regard that Arokodare and Asikhia (2020) posited that 21st-century organizations are always looking for means to continuously maintain business survival amidst global shock. Gerald et al. (2020) clarified that most organizations experienced difficulties surviving the periods of global shock, which resulted in the closure of markets for consumers and suppliers of products and/or services, and businesses have had to operate at a lower (or even zero) capacity.

This might spell death for organizations that are not agile, as they will not be able to successfully recover from this unfortunate circumstance. This could lead to the demise of many SMEs, be disastrous for Nigeria's economy, and result in the loss of sources of income and livelihood for many people. However, universities (organizations) cannot survive without strategic agility measures like strategic sensitivity, strategic response and collective capabilities as well as an agile organizational structure to manage and overcome the effects of the global pandemic and the attendant economic uncertainty. In this regard, Patton (2020) asserted that universities without agile structures failed to maintain performance sustainability in terms of market performance, student satisfaction, and sound operational management. An agile enterprise possesses the ability to sense, perceive and anticipate changes in the external environment and convert these changes into opportunities that are in favor of the organization (Zhang \& Shariff, 2000). There is therefore a need for a paradigm shift; a new way of doing things at times of crisis. This new paradigm usually comes with opportunities but that is opened to only those organizations that are prepared to adapt their strategies very swiftly, disrupt their existing business model and execute with speed (Couturier \& Sola, 2020). This is strategic agility (SA). This study is relatively novel in that to the best of the researcher's knowledge, few studies have examined SA and the pandemic in organizations in times of crisis and precarious situations such as the COVID-19 era (Amuda, 2020; Couturier \& Sola, 2020; Dai et al., 2020; Gerard et al., 2020; Liu et al., 2020). It is against this backdrop that this study was necessitated to look at how organizations, specifically higher educational institutions, could come out victorious from this situation through the application of SA initiatives. 


\section{Review of Literature}

Marketing: Marketing, which includes market research and advertisement, is the action or business of promoting and selling goods or services. Marketing is described by Lamb, Hair, McDaniel, Boshoff, and Terblanche (2007) as the process of anticipating and fulfilling customer needs through mutually beneficial exchange systems while doing so more profitably and efficiently than rivals using more robust managerial processes. Cronje, Du Toit, Motlatla, and Marais (2017) opined that marketing is the idea of a business correctly determining the needs and desires of particular target audiences, and then exceeding the competition in achieving the desired satisfactions.

Customer Satisfaction: Customer satisfaction is a psychological concept that encompasses the feeling of fulfillment and happiness that comes from receiving what one desires and expects (Rahim, 2017). "Satisfaction is the feeling of gratification or dissatisfaction that arises from contrasting the output (or outcome) of a product or service's perceived quality in relation to the buyer's expectation," (Kotler, 2001: 58). Customer satisfaction is described as an overall assessment of a product or service based on the cumulative purchase and usage experience with it over time (Rosenberg \& Czepiel, 1984). Customer satisfaction goes hand in hand with marketing, which means it establishes the expectation. As a result, actionable insight on how to improve customer satisfaction is a critical outcome (Hill, Roche, \& Allen, 2007). Customer satisfaction is a measurement that measures how satisfied consumers are with a company's goods, services, and capabilities. It is one of the most significant indicators of consumer purchasing. Consumer satisfaction has many important roles in the business world: it is a leading metric for determining customer loyalty, identifying dissatisfied customers, reducing rejection and withdrawal, and boosting sales (Chattopadhyay, 2019). In a dynamic market environment, it is also a crucial point of distinction that aids organizations in attracting new customers.

Operations Management: The structures or processes that produce products and provide services are referred to as operations management. It is the management of an organization's productive capital or output system, according to Krajewski, Ritzman, and Malhotra (2013). It is an area of management, according to Bellgran and Säfsten (2009) that is concerned with designing and managing the production process as well as redesigning business operations in the production of goods and services. According to Galvin (2009), operation management entails preparing, arranging, scheduling, and regulating all of the resources required to produce a company's products and services, as well as managing personnel, facilities, technology, records, and all other resources. However, based on the above concepts, operations management is the process of combining and transforming resources flowing within a given framework in a managed manner to add value in accordance with management policies.

Organizational Structure: It is the expression of systemic thought and is made up of fundamentals, relationships between fundamentals, and the structure of relationships as a whole (Ahmady et al., 2016). It is a tool for dividing, organizing and coordinating organizational activities, and its presence can make decisionmaking, appropriate environmental response, and dispute resolution between constituent units easier; thereby helping the information flow (Monavarian et al., 2007). Dove (2001) refers to organizational structure as "a collection of distinct resources or elements that are related as a group interacting together for some common purpose" (p. 11). Elements of organizational structure are outlined by Raziq, Ahmad, Iqbal, Ikramullah, and David (2020) to include: departmentalization, chain of command or complexity (the number of management levels in the organization), the span of control, centralization or decentralization. From literature, Ahmady et al. (2016) identified the factors determining structure to include goals and strategy (the process of determining long-term goals), size of the organization (physical capacity, number of employees, organization input and output, financial resources), technology (the information, equipment, techniques and process to turn the inputs to outputs), environment (general and specific) and control power (strategic selection of power owners of the organization).

Agile Organisational Structure: An agile organizational structure is a flat, non-hierarchical system of operating procedures that allows for more flexibility in business operations and responds quickly to shifts and changes in the market environment (Daft, 2020). Such organizational structure is characterized by fast activity cycles in learning and decision-making, customer-centricity, open communication, and a network of 
autonomous teams. In addition, an agile organization must have a flexible organizational structure, strong organizational culture, leadership unity, and entrepreneurial management skills. According to Doz and Kosonen (2008), strategically agile organizations learn to make fast turns, transform themselves without losing momentum, take advantage of change and disruption, and play the fast strategy game by thriving on continuous waves of change. These organizations implement the three dimensions of SA and their management and teams "perceive early, decide quickly, and strike with strength and speed" (Doz \& Kosonen, 2008: xi). Dove (2001) conceptualized agility from the perspective of the physical ability to act (responseability) and the intellectual ability to find appropriate things to act on (knowledge management). He, therefore, posited that agility is "the ability to manage and apply knowledge effectively so that an organization has the potential to thrive in a continuously changing and unpredictable business environment" (p. 9). Agile organizations are both stable and dynamic at the same time (Couturier \& Sola, 2020). They mobilize quickly, they are nimble, and they are empowered to act and make it easy to act. They are masters of change who are able to seize opportunities as well as initiate innovations, usually with fast speed.

Strategic Agility: Strategic agility (SA) was defined by Tallon and Pinsonneault (2011) as the ability of a company to respond fast to the changes in the business environment, adapt to the changes and take actions that are aimed at controlling uncertainty. Nazir and Pinsonneault (2012) described SA as the ability of sensing and responding to internal and external changes; Shin, Lee, Kim, and Rhim (2015) defined SA as an organization's strategic intent to maintain agile operations driven by an emphasis on improving responsiveness and adaptability to customers' needs and requirements; while Sampath and Krishnamothy (2017) saw SA as a multidimensional concept, which includes both the ability to detect, anticipate, sense market opportunities, evolving conditions, and other environmental changes and the ability to seize the opportunity with speed and implement new solutions. Queiroz, Tallon, Sharma, and Coltman (2018) defined it as the ability to detect and react in an agile manner, to threats and opportunities emerging from the environment. The common themes in these selected definitions of SA are business environment, changes (opportunities and threats) from the environment, and the capability and speed of the organization to detect and react to these changes. In line with these themes and the three-dimensional conceptualization of SA by Mavengere (2013) which was echoed by Anggraini and Sudhartio (2019), SA was defined by Arokodare (2020) as "the ability of the organization to sense changes in dynamic, fast-paced environments, and to quickly respond to these changes by seizing market opportunities and maintaining competitiveness through building, combining, enhancing, mobilizing and reconfiguring its capabilities and in the process attaining and sustaining superior performance beyond its competition" (p. 45).

This definition recognized the SA determinants and dimensions of strategic sensitivity, strategic response and collective capabilities and in addition, included the prime aim of the whole SA program, which is the ultimate objective of the organization being the attainment and sustenance of superior firm performance. The definition also recognized SA as a management tool for creating a competitive advantage for the organization as it becomes expedient for the organization not only to recognize its industry dynamics (internal and external) but also to respond to it through fast strategy to ensure survival by way of superior performance. It is the organization's penchant for adjusting its business model to the unpredictable changes of the business environment in order to achieve an increased level of value to the stakeholders (Arokodare, 2021b).

Empirical Review: Several empirical studies have established a positive and significant relationship between SA and organizational performance, with different indicators used for the latter: overall firm performance (Arokodare, 2021b); emotional and entrepreneurial ability (Khorshid, 2019); competitive advantage (AlRomeedy, 2019; Tse et al., 2016); external and internal learning (Khan \& Wisner, 2019); responsiveness to uncertainties (Tse et al., 2016); firm success and capturing of new opportunities (Kwon et al., 2018). Specifically, for organizations to cope with dynamic competition and survive today's market globalization trend especially in a COVID-19 pandemic-ridden environment as we have now, SA is a useful tool employed in the management style, process and decision making of these organizations (Arokodare, 2021b). The ultimate objective is the attainment of superior overall performance over market rivals. For example, Gerald et al. (2020) examined the impact of strategic foresight, a key dimension of SA, on the competitive advantage (as an indicator of firm performance) of SME's in the phase of the COVID-19 pandemic and found that strategic foresight had a statistically significant relationship with a competitive advantage. Ekweli and Hamilton (2020) found a significant relationship between product innovation and organizational agility in the Nigerian 
banking sector; Kwon, Ryu and Park (2018) revealed that the entrepreneurs' clear vision and solid SA are prerequisites for effective opportunity realization.

Lungu (2020) in a study of the IT sector in Romania, found that organizations that used SA have an improved performance level than their competitors. Specifically, on the higher education front, Menon and Suresh (2020a) in their study of organizational agility assessment for higher education institutions found that higher education institutions have been facing changes in the environment and that to stay competitive, colleges and universities need to leverage their resources and act proactively to capitalize on these changes. They confirmed that organizational agility assessment would help the institutions to recognize their current position, identify gaps and prepare for improvement in areas like sensing and responding to environmental changes, organizational structure, organizational culture, organizational learning and knowledge management, agile workforce and change management. Mukerjee (2014) recognized that SA was a necessary capability for universities in times of turbulence and recommended that they should develop and nurture agile capability to address their future challenges. On the strength of positive empirical findings between SA and organizational outcomes, this study proposes that:

Proposition 1: Strategic agility has a positive influence on organizational outcomes in institutions of higher education.

In an extensive review of literature, Arokodare (2020) identified some antecedents which are key ingredients necessary to achieving SA, both in conceptualization, implementation and in execution. Specifically, Teece, Peteraf, and Leih (2016) recognized entrepreneurial management and flexible organizational structure as two interdependent elements of the dynamically capable firm, as underpinnings of SA. This means that a strategically agile organization must have entrepreneurs who are capable of combining and recombining resources and technologies, who can sense the future, and who can seize on and act upon the future opportunities by developing critical insights and acting upon them ahead competitors. These entrepreneurs must also have the platform of a well-structured and flexible firm that can be rapidly modified and adapted. While the flexible organizational structure is recognized as an antecedent of SA, it is also a requirement for the proper performance of an organization during a global shock, like the COVID-19 pandemic. According to Ahmadi et al. (2012), to achieve agility, a company must constantly assess its personnel's efficiency and the importance of its goods and services, respond to frequent changes in its customers' needs, learn new things, provide a high information content, be ready to respond to unexpected changes and incidents, use emerging technology, and discover and leverage new opportunities. As a consequence, achieving agility necessitates organizational versatility and sensitivity in terms of tactics, technology, processes, and individuals. Fatani (2020) stated that attracting students to a university is always a competitive business. However, when you throw a global pandemic into the mix, the challenges around marketing higher education become even greater. He further stated that agile universities can react and adjust quickly using progressive marketing techniques such as content personalization and content targeting. Therefore, the agile university structure is succeeding and is pulling away from the others in terms of success.

UNESCO (2020) argued that the global pandemic has changed medical education the world over. The United Nations Educational, Scientific, and Cultural Organization (UNESCO) publicized that 1.5 billion students across the planet have been affected by school and university closures due to the pandemic. Consequently, faculty members in the universities shifted from in-person to distance education in order to facilitate students' education. This means that the majority of faculty members and students find it difficult to interact physically which directly reduced students' satisfaction (Fatani, 2020). Arokodare and Asikhia (2020) emphasized that most firms in Nigeria have recorded a decline in customer satisfaction due to slow strategic sensitivity and response to global shock. However, Richardson and Swan (2019) claimed that without sound agility measures and agile organizational structure, student satisfaction during a global pandemic will decline. Many empirical studies have been carried out on the impact of organizational structure on various items of organizational outcomes. In a study of the relationship between organizational structure and organizational agility in an insurance company, Ahmadi et al. (2012) found that there was a significant relationship between organizational agility and formalization and centralization dimensions of organizational structure; but no relationship was established with the complexity dimension. Sampath and Krishnamoorthy (2017) investigated the impact of SA on competitive advantage in Indian retail banks and found that organizational factors (organizational structure, organizational goals, policies, etc) influenced the firms' profitability more 
than that of economic factors. Tahernezhad et al. (2013) in a case study of a revenue agency located in the province of Alborz in Iran, found meaningful relationships between organizational components of formality, complexity and authority and learning capability and none between the components of concentration and flexibility and learning capability. Ogbo et al (2015) investigated the impact of structure on organizational performance in technical and service firms in Nigeria and found that decentralization enhanced better and more informed decision making in technical and service firms in Nigeria; that task routine affected staff productivity both positively and negatively; and that a significant positive relationship existed between narrow span of control and efficiency in organizations.

Universities experience a fast-changing and increasingly global business competitive environment which determines operational management and efficiency (Arokodare, Asikhia, \& Makinde, 2019; Sadjak, 2015). Vidmar, Rosiello, and Golra (2020) examined the case for SA in the resilience of the new space firms in the UK in the early stages of the COVID-19 pandemic and found a significant level of SA among the studied sample as organizational restructuring and new organizational culture were quickly mobilized based on transparent leadership from management teams. Tende and Ekanem (2018) stated that organizations (and universities) with SA features such as strategic sensitivity, strategic response and collective capabilities were able to predict, anticipate, and forecast trends and events in the business environment and fashion appropriate response with proactive moves to manage global shocks. Akhigbe and Onuoha (2019) posited that it is no longer the fittest organizations (universities) that last longer, but organizations (universities) with high resilience, sensitivity and capacity to adjust towards local and global shocks. This indicates that the operational survival of Universities or organizations is no longer determined by financial muscle or capital alone, but more importantly by the ability to adjust to changes in the uncertain business environment with speed in strategic decisions and commitments. Based on the above review, this paper proposes that:

Proposition 2: Flexible organizational structure has a positive mediating influence on the relationship between strategic agility and organizational outcomes.

\section{Theoretical Foundations and Conceptual Model Development}

This sub-section focused on the theoretical foundation and how the anchored or foundation theory relates with the conceptual model of this study. This study was theoretically anchored on Dynamic Capabilities Theory (DCT) as baseline theory since the DCT dynamically explains how firms could react and respond to uncertain features of the business environment so as to survive economic risk hurdle and gain overall performance. This theory was selected to guide the study because its perspectives are tied to the focus of the study and the variables under investigation and its theoretical explanation of the study objectives in relation to the conceptual model of the study. The DCT is the capability of an organization to purposefully adapt an organization's resource base. Dynamic capabilities theory (DCT), which was developed by Teece, Pisano and Shuen (1997) was defined as "the firm's ability to integrate, build, and reconfigure internal and external competencies to address rapidly changing environments" (p. 516) and it examines how firms address or bring about changes in their turbulent business environment through reconfiguration of their firm-specific competencies into new competencies (Teece, 2007).

The DCT system is based on three fundamental assumptions: the ability to detect and form opportunities, the ability to seize certain opportunities, and the ability to sustain competitiveness by asset reconfiguration (Teece, 2007). Dynamic capabilities, according to Easterby-Smith, Lyles, and Peteraf (2009), are higher-level capabilities that allow information gathering, quick response, sharing, and continuous updating of operational processes, interaction with the environment, and decision-making assessments in order to achieve firm competitive advantages and efficiency. Dynamic skills, according to Esbach (2009), are an organization's ability to purposefully build an agile firm and change its resource base to achieve a competitive edge and improve other performance metrics such as marketing, customer loyalty, and operations management. Dynamic capabilities, therefore, involve the sensing, seizing, and transforming abilities required to upgrade an enterprise's ordinary capabilities and guide them through the development and coordination of the firm's resources in order to resolve and shape changes in the marketplace or the business climate (Teece, 2018). 
Since the DCT viewpoints and philosophy were tied to the assumption that companies dynamically manipulate their capital and business environment in order to achieve competitive advantage and obtain overall organizational results in marketing customer loyalty, and operations management over their industry rivals, the DCT theory was used as the underlying, theory for this analysis. From the perspectives of the anchor theory, this study, therefore, established an interaction conceptual model between SA and organizational outcomes dimensions with the mediating role of agile or flexible organizational structure. In this study, the conceptual model shows the link between the dependent variable $(\mathrm{Y})$ and the independent variable $(\mathrm{X})$ with the mediating variable $(\mathrm{Z})$. The dependent variable is Organisational Outcomes which was conceptualized as: marketing, customer satisfaction and operations management; the independent variable $(\mathrm{X})$ is Strategic Agility with the dimensions of strategic sensitivity, strategic response and collective capabilities; while Flexible Organisational Structure mediates the relationship between Strategic Agility and Organisational Outcomes. This is based on the variables' conceptual measurement gap identified in the literature relating to the link between strategic agility and organizational outcomes. This conceptual model is depicted below in figure 1.

Figure 1: Research Conceptual Model

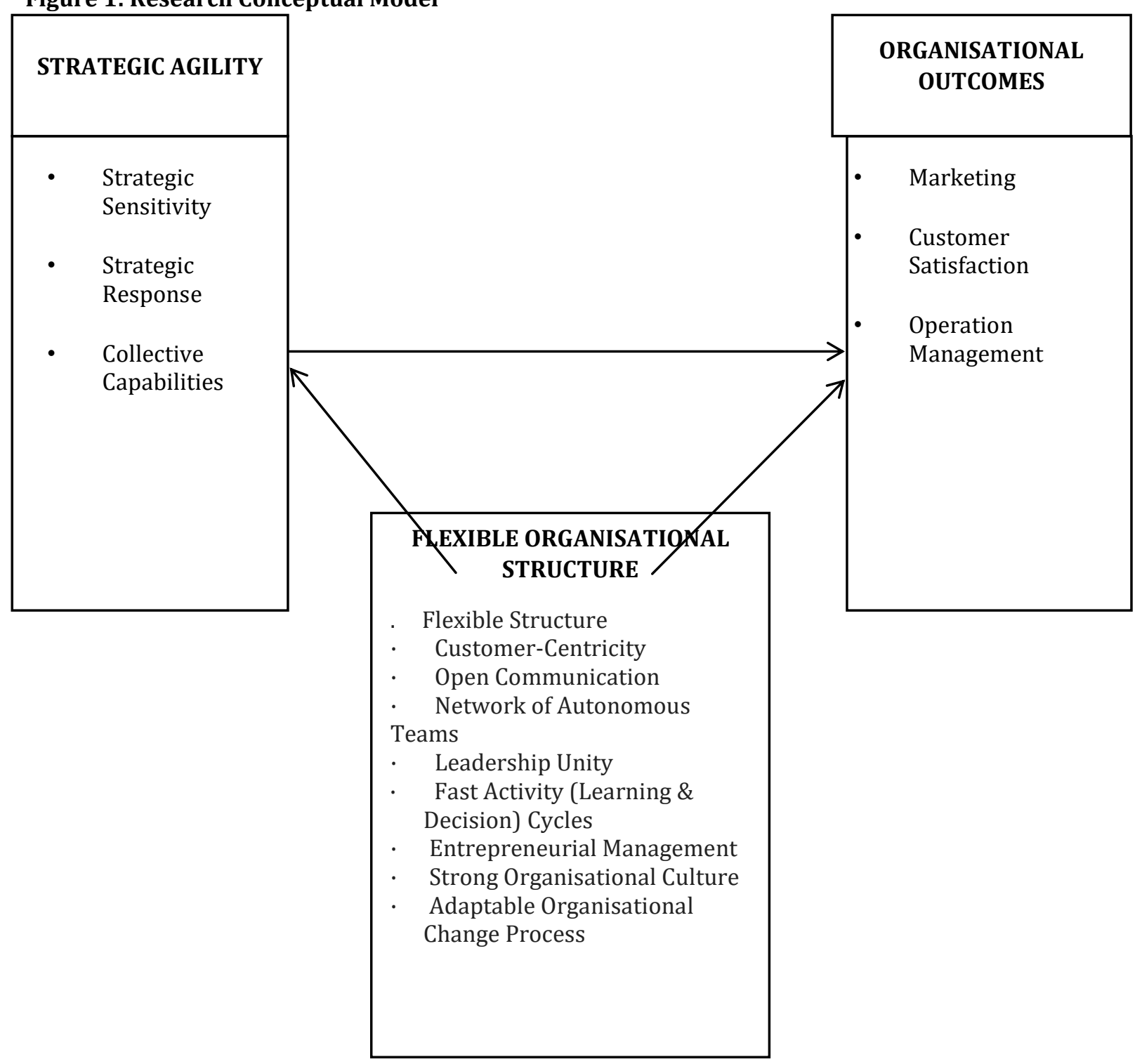

Source: Research Conceptual Model (2021) 
Most organizations across the globe have the intention to be strategically agile by adopting one or all the dimensions of strategic sensitivity, strategic response and collective capabilities towards developing the requisite, capabilities to match unforeseen shock as well as achieve targeted organizational outcomes in terms of marketing strength, customer satisfaction and sound operations management. However, possession of the flexible organizational structure that is necessary to pilot these intentions (strategic agility and organizational outcome measures) has become a great challenge to most of these organizations, especially the public university institutions in Nigeria. Therefore, organizations or university/higher education institutions with full capability of flexible organizational structure will be able to pilot and mediate the SA dimensions towards achieving the desired organizational outcomes (Foss \& Klein, 2005).

\section{Conclusion and Recommendations}

This study provides relevant conceptual definitions and interaction links between SA, organizational structure, and organizational outcomes. It also highlights the conceptual model that can be used by researchers to measure the mediating effect of flexible organizational structure on the relationship between SA and organizational outcomes. Given the number and degree of uncertainty and shocks in the global business environment, the enormity and pervasiveness of the disruptions caused by the COVID-19 pandemic in a contemporary business environment, the need for robust development of SA capabilities cannot be overemphasized. Such capabilities will enhance the ability of leaders to respond in real-time to change and uncertainty. Specifically, SA is a practical, project-based learning experience that supports administrators to engage in strategic thinking and strategic learning in ways that impact both organizational development and personal leadership development simultaneously. It builds leaders' capacity for strategic thinking, skill development, and a greater openness to leading school improvement and change initiatives.

Based on the foregoing, the study, therefore, made the following recommendations to the management of institutions of higher education:

- The institutions must be able to think strategically with an agile mindset: the ability to anticipate the new future of opportunities and discoveries, willingness to embrace the turmoil and embed a love of experimentation and problem solving into the institution's processes.

- Following from (1) above, the institutions must show readiness to understand mistakes, learn lessons quickly, and change the underlying assumptions (the dominant logic) quickly and repeatedly until successful.

- A strategically agile institution must continuously adjust and readjust its strategic direction in order to develop innovative ways to create value (Weber \& Tarba, 2014). This will be done by bringing together dynamic capabilities like strategic sensitivity, strategic response, collective capabilities (Mavengere, 2013) in a way that creates and sustains flexibility without losing efficiency.

- Academic and non-academic staff teams should be empowered on dynamic and modern marketing approaches to manage unexpected events in order to improve marketing performance.

- Universities should find a commercial and emotional reason to change and be agile to enhance an agile organizational structure and the ability to respond fast to an unexpected event.

- Universities should identify and support real change agents in the schooling business as this will enhance university students' satisfaction.

- The flexibility of the organizational structure should be improved through decentralization and the adoption of flexible structures.

- Ensure greater delegation of authority and use of training and education as critical learning tools to enhance the human resource capability of a strategically agile organization.

- Investment in contemporary and appropriate technology that can respond to changes in students' requirements and offer appropriate services to them.

- Flexible systems of service offerings should be adopted in various areas of students' needs: from admission processing to student registration, course registration, and delivery of lectures and seminars. 


\section{Limitations and Suggestions for Further Studies}

This conceptual and theoretical review paper is a study of SA and a flexible and agile organizational structure in an era of a global pandemic from various perspectives and viewpoints of several scholars. It is a reference to what has been done so far as regards the conceptual link between the study variables in the process of understanding both the concept of agile organizational structure and the study of SA as a useful management tool in times of extreme environmental turbulence. Therefore, future studies should empirically investigate the mediating effect of flexible organizational structure on the relationship between strategic agility and organizational outcomes in different industries of the economy. Moreover, the impact of the various dimensions of SA (strategic sensitivity, strategic response, collective capabilities) on the SA-organisational outcome relationship should be investigated as the individual dimensions can have a differential impact on the relationship, depending on many contextual factors. Finally, it will be very useful for the enablers of agility in higher education as enunciated in Menon and Suresh (2020b) to be empirically investigated both for their completeness and also their relevance in a different geographical jurisdiction like Nigeria.

\section{References}

Aga, G., Francis, D. C. \& Meza, J. R. (2015). SMEs, age, and jobs: A review of the literature, metrics, and evidence. Policy Research Working Paper 7493. World Bank Group.

Aghina, W., De Smet, A. \& Weerda, K. (2015). Agility: It rhymes with stability. McKinsey Quarterly, 51(4), 2-9.

Ahmadi, S. A. A., Fathizadeh, A., Sadeghi, J., Daryabeigi, M. \& Taherkhani, L. (2012). A study on the relationship between organizational structure and organizational agility: A case study of insurance firm. Management Science Letters, 2(8), 2777-2788.

Ahmady, G. A., Mehrpour, M. \& Nikooravesh, A. (2016). Organizational structure. Procedia-Social and Behavioral Sciences, 230, 455-462.

Akhigbe, E. A. \& Onuoha, B. C. (2019). Strategic agility and organizational resilience of food and beverage firms in Rivers State, Nigeria. International Journal of Business Systems and Economics, 12(2), 80-93.

Al-Romeedy, B. S. (2019). Strategic agility as a competitive advantage in airlines-Case study: Egypt Air. Journal of the Faculty of Tourism and Hotels-University of Sadat City, 3(1), 1-15.

Amuda, Y. J. (2020). Impact of coronavirus on small and medium enterprises (SMEs): Towards post-COVID-19 economic recovery in Nigeria. Academy of Strategic Management Journal, 19(6), 1-11.

Anggraini, W. \& Sudhartio, L. (2019). Strategic agility in environmental turbulence. A case of the banking sector in Indonesia. Conference Proceedings of the 1st Sampoerna University-AFBE International Conference, SU-AFBE 2018, 6-7 December 2018, Jakarta Indonesia.

Arokodare, M. A. (2020). Strategic agility and firm performance of selected oil and gas marketing companies in Lagos State, Nigeria. (Ph.D. Thesis). Babcock University, Nigeria.

Arokodare, M. A. (2021b). Do strategic agility measures affect overall firm performance of oil and gas industry? An empirical investigation. European Journal of Business and Management, 13(3), 31-42.

Arokodare, M. A. \& Asikhia, O. U. (2020). Strategic agility: Achieving superior organizational performance through strategic foresight. Global Journal of Management and Business Research: Administration and Management, 20(3), 7-16.

Arokodare, M. A., Asikhia, 0. U. \& Makinde, G. 0. (2019). Strategic agility and firm performance: The moderating role of organizational culture. Business Management Dynamics, 9(3), 01-12.

Bellgran, M. \& Säfsten, K. (2009). Production Development: Design and operation of production systems. Springer. London.

Chattopadhyay, P. (2019). A study on the impact of service quality on customer satisfaction and customer loyalty with reference to service marketing context: Theoretical approach. Iconic Research and Engineering Journals, 3(1), 89-96.

Chen, Y., Wang, Y., Nevo, S., Jin, J., Wang, L. \& Chow, W. S. (2014). IT capability and organizational performance: the roles of business process agility and environmental factors. European Journal of Information Systems, 23(3), 326-342.

Ciotti, M., Ciccozzi, M., Terrinoni, A., Jiang, W. C., Wang, C. B. \& Bernardini, S. (2020). The CoVID-19 pandemic. Critical Reviews in Clinical Laboratory Sciences, 57(6), 365-388.

Couturier, J. \& Sola, D. (2020). Strategic agility in time of crisis. Ecole Superieure de Commerce de Paris (ESCP) Working Paper No. 2020-32-EN. 
Cronje, G. J., Du Toit, G. S., Motlatla, M. D. C. \& Marais, A. de K. (2007). Introduction to Business Management (6th Ed.). Cape Town: Oxford University Press.

Daft, R. L. (2020). Organization theory \& design. Cengage Learning.

Dai, R., Feng, H., Hu, J., Jin, Q., Li, H., Wang, r., Wang, R., Xu, L. \& Zhang, H. (2020). The impact of COVID-19 on small and medium-sized enterprises (SMEs): Evidence from two-wave phone surveys in China. Centre for Global Development Working Paper 549.

Doh, J., Rodrigues, S., Saka-Helmhout, A. \& Makhija, M. (2017). International responses to institutional void. Journal of International Business Studies, 48, 293-307.

Dove, R. (2001). Response-ability: The language, structure, and culture of the agile enterprise. New York, NY: John Wiley \& Sons.

Doz, Y. L. \& Kosonen, M. (2008). Fast Strategy: How strategic agility will help you stay ahead of the game. Wharton School Publishing. Pearson Education.

Esbach, J. (2009). Relevance of engineering entrepreneurship: A study at the Cape Peninsula University of Technology. Journal of Asia Entrepreneurship and Sustainability, 5(3), 108.

Easterby-Smith, M., Lyles, M. A. \& Peteraf, M. A. (2009). Dynamic capabilities: Current debates and future directions. British Journal of Management, 20, S1-S8.

Ekweli, F. \& Hamilton, D. I. (2020). Product innovation and organizational agility in the banking sector of Nigerian economy. Global Science Journal, 8(1), 171-188.

Fatani, T. H. (2020). Student satisfaction with videoconferencing teaching quality during the COVID-19 pandemic. BMC Medical Education, 20(396), 2-8.

Foss, N. J. \& Klein, P. G. (2005). Entrepreneurship and the economic theory of the firm: Any gains from trade? In Handbook of Entrepreneurship Research (pp. 55-80). Boston, MA: Springer.

Galvin, P. (2009). Product modularity and the contextual factors that determine its use as a strategic tool. Curtin University of Technology, Perth.

Gerald, E., Obianuju, A. \& Chukwunonso, N. (2020). Strategic agility and performance of small and medium enterprises in the phase of Covid-19 pandemic. International Journal of Financial, Accounting, and Management, 2(1), 41-50.

Gholam A., Maryam M. \& Aghdas, N. (2016). Organizational structure. Procedia-Social and Behavioral Sciences, $230,455-462$.

Govuzela, S. \& Mafini, C. (2019). Organizational agility, business best practices and the performance of small to medium enterprises in South Africa. South African Journal of Business Management, 50(1), 1417.

Hill, N., Roche, G. \& Allen, R. (2007). Customer Satisfaction: The customer experience through the customer's eyes. London: Cogent Publishing Ltd.

Khan, H., \& Wisner, J. D. (2019). Supply chain integration, learning, and agility: Effects on performance. Journal of Operations and Supply Chain Management, 12(1), 14-23.

Khorshid, S. (2019). The impact of organization's strategic agility and emotional capability on entrepreneurship-orientation (Case study: The University of Khashan and Qom cities). Management in the Islamic University, 14(6), 238-262.

Kotler, P. (2001). A framework for marketing management. Englewood Cliffs, N.J.: Prentice-Hall.

Krajewski, L. J., Ritzman, L. P. \& Malhotra, M. K. (2013). Operations Management. Pearson.

Kwon, S. J., Ryu, D. \& Park, E. (2018). The influence of entrepreneur's strategic agility and dynamic capability on the opportunity pursuit process of new ventures: Evidence from South Korea. Academy of Strategic Management Journal, 17(1), 1-17.

Lamb, C. W. Jr., Hair, J. F., McDaniel, C., Boshoff, C. \& Terblanche, N. S. (2007). Marketing. 2nd South African edition. Cape Town: Oxford University Press.

Liu, Y., Lee, J. M. \& Lee, C. (2020). The challenges and opportunities of a global health crisis: The management and business implications of COVID-19 from an Asian perspective. Asian Business \& Management, 19, 277-297.

Lungu, M. F. (2020). The influence of strategic agility on firm performance. Proceedings of the 14th International Conference on Business Excellence, 102-110.

Mavengere, N. B. (2013). Information technology role in supply chain's strategic agility. International Journal of Agile Systems and Management, 6(1), 7-24.

Menon, S. \& Suresh, M. (2020a). Organizational agility assessment for higher education institution. The Journal of Research on the Lepidopetra, 51(1), 561-573. 
Menon, S. \& Suresh, M. (2020b). Factors influencing organizational agility in higher education. Benchmarking: An International Journal (Ahead of Print).

Monavarian, A., Asgari, N. \& Ashena, M. (2007). Structural and content dimensions of knowledge-based organizations. The first national conference of knowledge management. Bahman 2007.

Mukerjee, S. (2014). Organizational agility in universities: Tensions and challenges. In Fitzgerald, T. (ed.) Advancing Knowledge in Higher Education: Universities in Turbulent Times (pp. 15-25). Hershey, PA: IGI Global.

Nazir, S. \& Pinsonneault, A. (2012). IT and firm agility: An electronic integration perspective. Journal of the Association for Information Systems, 13(3), 150-171.

Nnamani, E. \& Ajagu, H. E. (2014). Environmental factors and organizational performance in Nigeria: A study of Juhel Company. World Engineering \& Applied Sciences Journal, 5(3), 75-84.

Ogbo, A. I., Chibueze, N. F., Christopher, O. C. \& Anthony, I. A. (2015). The impact of structure on organizational performance of selected technical and service firms in Nigeria. Corporate Ownership \& Control, 13(1), 1278-1284.

Patton, D. (2020). Food exporters to China asked to declare produce is coronavirus-free [Online].

Queiroz, M., Tallon, P. P., Sharma, R. \& Coltman, T. (2018). The role of IT application orchestration capability in improving agility and performance. The Journal of Strategic Information Systems, 27(1), 4-21.

Rahim, A. G. (2017). Customer satisfaction and loyalty: A study of interrelationships and effects in Nigerian domestic airline industry. Oradea Journal of Business and Economics, 2(1), 7-20.

Raziq, M. M., Ahmad, M., Iqbal, M. Z., Ikramullah, M. \& David, M. (2020). Organizational structure and project success: The mediating role of knowledge sharing. Journal of Information \& Knowledge Management, 19(2), 2050007.

Richardson, J. C. \& Swan, K. (2019). Examining social presence in online courses in relation to students' perceived learning and satisfaction. Online Learn, 7(1), 68-88.

Rodgers, P. (2020). Strategic agility in uncertain times. The Open University Business School.

Rosenberg, L. J. \& Czepiel, J. A. (1984). A marketing approach for customer retention. Journal of Consumer Marketing, 1(2), 45-51.

Rugraff, E. \& Hansen, M. W. (2011). Multinational corporations and local firms in emerging economies: An introduction. In E. Rugraff \& M. W. Hansen (Eds.), Multinational corporations and local firms in emerging economies (pp. 1-47). Amsterdam, Netherlands: Amsterdam University Press.

Sajdak, M. (2015). Compilation of operational and strategic agility for ensuring the highest efficiency of company operations. Economics and Management, 7(2), 20-25.

Sampath, G. \& Krishnamoorthy, B. (2017). Is strategic agility the new Holy Grail? Exploring the strategic agility construct. International Journal of Business Excellence, 13(2), 160-180.

Shin, H., Lee, J. N., Kim, D. \& Rhim, H. (2015). Strategic agility of Korean small and medium enterprises and its influence on operational and firm performance. International Journal of Production Economics, 168, 181-196.

Tahernezhad, K., Sadaghiani, J. S. \& Ghaiyoomi, A. (2013). A study on the relationship between organizational structure and learning characteristics: A case study of revenue agency. Management Science Letters, 3(3), 991-994.

Tallon, P. P. \& Pinsonneault, A. (2011). Competing perspectives on the link between strategic information technology alignment and organizational agility: Insights from a mediation model. MIS Quarterly, 35, 63-486.

Teece, D. J. (2007). Explicating dynamic capabilities: The nature and micro-foundations of (sustainable) enterprise performance. Strategic Management Journal, 28(13), 1319-1350.

Teece, D. J. (2018). Business models and dynamic capabilities. Long Range Planning, 51(1), 40-49. https://doi.org/10.1016/j.lrp.2017.06.007

Teece, D., Peteraf, M. \& Leih, S. (2016). Dynamic capabilities and organizational agility: Risk, uncertainty, and strategy in the innovation economy. California Management Review, 58(4), 13-35.

Teece, D. J., Pisano, G. \& Shuen, A. (1997). Dynamic capabilities and strategic management. Strategic Management Journal, 18(7), 509-533. https://www.jstor.org/stable/3088148

Tende, F. B. \& Ekanem, I. S. (2018). Strategic agility: An intervention prescription to competitive advantage of small businesses in Nigeria. International Journal of Business Systems and Economics, 6(4), 14011423. 
Tse, Y. K., Zhang, M., Akhtar, P., \& MacBryde, J. (2016). Embracing supply chain agility: An investigation in the electronics industry. Supply Chain Management: An International Journal, 21(1), 140-156.

United Nations Educational, Scientific and Cultural Organisation (UNESCO). (2020). The futures of education after COVID-19. Regional Dialogue Synthesis Report.

Vidmar, M., Rosiello, A. \& Golra, O. (2020). Resilience of new space firms in the United Kingdom during the early stages of COVID-19 crisis: The case for strategic agility. New Space, 8(4), 172-178.

Weber, Y. \& Tarba, S. Y. (2014). Strategic agility: A state-of-the-art introduction to the special section on strategic agility. California Management Review, 56(3), 5-12.

Zhang, Z. \& Sharifi, H. (2000). A methodology for achieving agility in manufacturing organizations. International Journal of Operations \& Production Management, 20(4), 496-513. 